For reprint orders, please contact: reprints@futuremedicine.com

\section{Re-do craniotomy for recurrent glioblastoma}
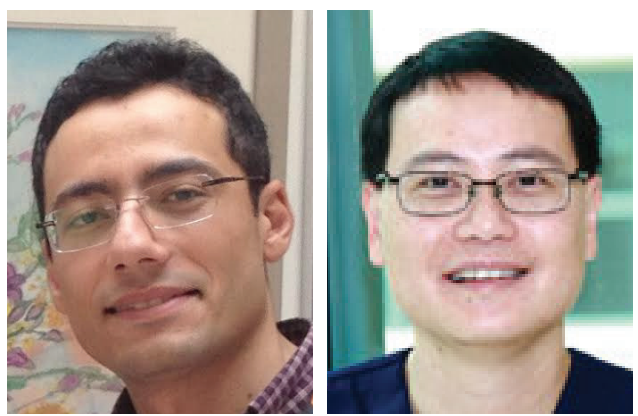

\author{
"Re-do craniotomy for \\ selected patients can lead to \\ significantly improved \\ functional outcomes and \\ survival. The morbidity of \\ re-do craniotomy is \\ acceptably low.”
}

\section{CNS Oncology}

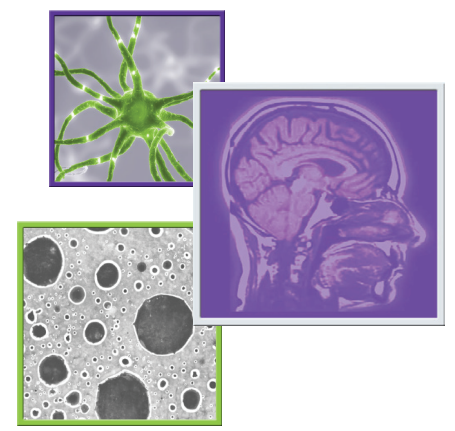

Ahmed A Morsy ${ }^{1,3}$ \& Wai Hoe $\mathrm{Ng}^{*, 1,2}$

Glioblastoma multiforme (GBM) is a WHO grade IV astrocytoma and the most common type of primary brain tumor in adults. The incidence rate for glioblastoma is approximately $3-4 / 100,000$ person years but varies to some extent in different regions of the world [1]. There has been little improvement in outcomes in spite of advances in adjuvant therapy over the past two decades, with the median duration of survival remaining at $12-15$ months $[2,3]$. The current protocol in the treatment of newly diagnosed glioblastoma includes surgical resection or biopsy, followed by concomitant radiochemotherapy with temozolomide followed by 6 additional months of adjuvant temozolomide [3]. In newly diagnosed glioblastoma, methylation of the O6-methylguanine DNA methyltransferase promoter has been shown to predict response to alkylating agents such as temozolomide, 1,3-bis(2-chloroethyl)1-nitrosourea (BCNU; carmustine) and cyclophosphamide [4].

There is evidence that the extent of resection for the primary treatment of GBM can lead to significant improvement in survival. Significantly, the threshold of greater than $78 \%$ resection based on volumetric assessment of enhancing tumor has been advocated with incremental improvements with increasing extent of resection. Many technological advances have been developed to improve the safety and completeness of resections, such as neuronavigation, functional mapping, intraoperative vital dyes and intraoperative imaging [5].

Despite optimal therapy, the estimated recurrence rate is in excess of $90 \%$ with no standard regimen and limited effective options for treatment. Whilst the role of initial aggressive resection is increasingly becoming standard practice, the role of re-do craniotomy for recurrent GBM is still highly controversial. A review of 31 studies investigating reoperation for recurrent high-grade glioma by HerveyJumper et al. found that 29 studies demonstrated a survival benefit of reoperation at recurrence [6].

With the improvement in surgical techniques and adjuvant treatment modalities, many patients are now surviving to

\section{KEYWORDS}

- glioblastoma multiforme

- guidelines • progression

- recurrence $\bullet$ re-operation 
recurrence with good functional status. The indications for repeat surgery include individuals with new focal neurological deficit, tumor mass effect with altered consciousness or radiographic evidence of tumor progression without clinical deterioration. Surgery can also differentiate tumor recurrence from pseudo-progression or radiation necrosis. But with the absence evidence-based guidelines it is essential to determine treatment goals and the effect on survival and quality of life for the patient.

Age and Karnofsky performance status (KPS) are useful prognostic factors. Many studies have also suggested that tumor size is an independent predictor of outcome [7]. Other predictors of improved survival include longer interval between operations and histopathology as radiation necrosis at time of reoperation. Stark et al. [8] studied the effects of advanced patient age for primary and recurrent highgrade glioma and the multivariate analysis for patients more than 60 years of age revealed independent associations with patients receiving reoperation at recurrence, in addition to greater extent of resection and use of radiation therapy as predictors for better outcome. This suggests that reoperation should be considered in all patients with a favorable performance status regardless of age [8]. There have been efforts to establish a preoperative scale to predict survival after repeated surgery; one such scale is the National Institutes of Health Recurrent GBM Scale, which is based on factors such as tumor involvement of eloquent/critical brain regions, KPS and tumor volume [9]. Another scoring system had been introduced based on KPS and ependymal involvement of the tumor in the MR images at recurrence [10]. These scores have not been extensively validated and have not been widely adopted.

The role of extent of resection at recurrence is still questionable. Data from two recent published series [11,12] recommend extent of resection at recurrence as important predictor of overall survival and its importance at reoperation even with patients with initial subtotal resections [12].

With the advent of advancements in neurosurgical techniques, neuro-anesthesia and neurocritical care, the perioperative complications with repeated surgeries have decreased greatly. It has even been reported that there is no significant difference in perioperative complications with initial craniotomy at diagnosis or repeat craniotomy at recurrence [13]. Implantation of biodegradable chemotherapy wafers (e.g., wafers with carmustine) at the time of repeat surgery may prolong survival; however, this practice remains highly controversial [14]. Preliminary evidence suggests that survival may be improved in patients with O6-methylguanine DNA methyltransferase promoter hypermethylation at recurrence [15], but may be adversely affected by postoperative complications such as bone marrow suppression, infection and poor wound healing [16]. With the widespread use of anti-angiogenic therapies, caution should be taken regarding wound healing complication when reoperating on any patient who has been treated with bevacizumab within 1 month of surgery [17].

In summary, while there is a paucity of definitive evidence supporting re-do craniotomy for recurrent glioblastoma, there is emerging data that subsets of patients can benefit significantly with improved functional outcomes and survival. There is also evidence to demonstrate that the morbidity of re-do craniotomy is acceptably low. It is recommended that patient selection for repeated surgery should be made according to individual circumstances guided with the available data in the literature and in consultation with the multidisciplinary team including neurosurgery, neuropathology, radiation oncology, neuro-oncology and allied health professions with comprehensive patient counseling.

With the present limitations and selection bias in the literature with reagrd to sample size and heterogeneity of treatment options at time of recurrence, the need for prospective large series data is crucial to establish more conclusive evidence for the role of re-do craniotomy for recurrent glioblastoma.

Financial \& competing interests disclosure The authors have no relevant affliations or financial involvement with any organization or entity with a financial interest in or financial conflict with the subject matter or materials discussed in the manuscript. This includes employment, consultancies, honoraria, stock ownership or options, expert testimony, grants or patents received or pending, or royalties.

No writing assistance was utilized in the production of this manuscript. 


\section{References}

1 Deorah S, Lynch CF, Sibenaller ZA, Ryken TCR. Trends in brain cancer incidence and survival in the United States: Surveillance, Epidemiology, and End Results program, 1973 to 2001. Neurosurg. Focus 20(4), E1 (2006).

2 Laws ER, Parney IF, Huang W et al. Survival following surgery and prognostic factors for recently diagnosed malignant glioma: data from the Glioma Outcomes Project. J. Neurosurg. 99, 467-473 (2003).

3 Stupp R, Mason WP, van den Bent MJ et al. Radiotherapy plus concomitant and adjuvant temozolomide for glioblastoma. N. Engl. J. Med. 352, 987-996 (2005).

4 Esteller M, Garcia-Foncillas J, Andion E et al. Inactivation of the DNA-repair gene $M G M T$ and the clinical response of gliomas to alkylating agents. N. Engl. J. Med. 343, 1350-1354 (2000).

5 Sanai N, Polley MY, McDermott MW, Parsa AT, Berger MS. An extent of resection threshold for newly diagnosed glioblastomas. J. Neurosurg. 115, 3-8 (2011).

6 Hervey-Jumper AL, Berger MS. Reoperation for recurrent high grade glioma: a current perspective of the literature. Neurosurgery 75(4), 491-499 (2014).

7 Brandes AA, Franceschi E. Reoperation for recurrent gliobastoma: outcome analysis and correlation with MGMT status. Eur. Assoc. Neurooncol. Mag. 4(1), 16-19 (2014).

8 Stark AM, Hedderich J, Held-Feindt J, Mehdorn HM. Glioblastoma: the consequences of advanced patient age on treatment and survival. Neurosurg. Rev. 30(1), 56-61 (2007).

9 Park JK, Hodges T, Arko L et al. Scale to predict survival after surgery for recurrent glioblastoma multiforme. J. Clin. Oncol. 28(24), 3838-3843 (2010).

10 Park C, Kim JH, Nam D et al. A practical scoring system to determine whether to proceed with surgical resection in recurrent glioblastoma. Neuro Oncol. 15(8), 1096-1101 (2013).

11 McGirt MJ, Chaichana KL, Gathinji M et al. Independent association of extent of resection with survival in patients with malignant brain astrocytoma. J. Neurosurg. 110(1), 156-162 (2009).

12 Bloch O, Han SJ, Cha S et al. Impact of extent of resection for recurrent glioblastoma on overall survival: clinical article. J. Neurosurg. 117(6), 1032-1038 (2012).

13 Chang SM, Parney IF, McDermott M et al. Perioperative complications and neurological outcomes of first and second craniotomies among patients enrolled in the Glioma Outcome Project. J. Neurosurg. 98(6), 1175-1181 (2003).
14 Brem H, Piantadosi S, Burger PC et al. Placebo-controlled trial of safety and efficacy of intraoperative controlled delivery by biodegradable polymers of chemotherapy for recurrent gliomas. The Polymer-brain Tumor Treatment Group. Lancet 345, 1008-1012 (1995).

15 Metellus P, Coulibaly B, Nanni I et al. Prognostic impact of O6-methylguanineDNA methyltransferase silencing in patients with recurrent glioblastoma multiforme who undergo surgery and carmustine wafer implantation: a prospective patient cohort. Cancer 115, 4783-4794 (2009).

16 Reithmeier T, Graf E, Piroth T, Trippel M, Pinsker MO, Nikkhah G. BCNU for recurrent glioblastoma multiforme: efficacy, toxicity and prognostic factors. BMC Cancer 10, 30 (2010).

17 Clark AJ, Butowski NA, Chang SM et al. Impact of bevacizumab chemotherapy on craniotomy wound healing. J. Neurosurg. 114(6), 1609-1616 (2011).

18 Easaw JC, Mason WP, Perry J et al. Canadian recommendations for treatment of recurrent or progressive glioblastoma multiforme. Curr. Oncol. 18, e126-e136 (2011).

19 Helseth R, Helseth E, Johannesen TB et al. Overall survival, prognostic factors, and repeated surgery in a consecutive series of 516 patients with glioblastoma multiforme. Acta Neurol. Scand. 122(3), 159-167 (2010). 